\title{
Three Pathways to Highly Energy Efficient Buildings: Assessing Combinations of Teaming and Technology Hoda Homayouni ${ }^{1}$; Carrie Sturts Dossick P.E, M.ASCE${ }^{2}$; Gina Neff ${ }^{3}$
}

\author{
Forthcoming in Journal of Management in Engineering \\ https://doi.org/10.1061/(ASCE)ME.1943-5479.0000883
}

Accepted for Publication 9 September 2020

\begin{abstract}
Highly energy efficient (HEE) buildings require a whole-system approach to building design. Scholars have suggested many tools, techniques, and processes to address the cross-disciplinary complexities of such an approach, but how these elements might be best combined to lead to better project outcomes is yet unknown. To address this, we surveyed architects associated with 33 AIACOTE award-winning projects on the social, organizational, and technological elements of wholesystem design (WSD) practices. We then used fuzzy sets-Qualitative Comparative Analysis (fsQCA) to analyze the interdependencies among those elements. We found three distinct pathways for design and construction of HEE buildings: information-driven, process-driven, or organizationdriven. We also found that HEE buildings share some conditions for success, including having shared goals, owners' engagement in the design process, and frequent and participatory interorganizational meetings. Our findings can help practitioners strategize and make decisions on incorporating WSD elements associated with their project types. Moreover, these results provide a
\end{abstract}

\footnotetext{
${ }^{1}$ Teaching Associate, College of Architecture and Urban Planning, Iran University of Science and Technology, Tehran, Iran (corresponding author), E-mail: hoda@uw.edu

${ }^{2}$ Associate Professor, Department of Construction Management, University of Washington, Seattle, Washington, USA. E-mail: cdossick@uw.edu

${ }^{3}$ Professor of Technology \& Society, Oxford Internet Institute and Department of Sociology, University of Oxford, Oxford, UK. E-mail: gina.neff@oii.ox.ac.uk
} 
launch pad for scholars to investigate complementarities among elements facilitating the design and construction process of HEE projects.

Key words: whole system design, energy efficient buildings, Building Information Modeling, Integrated project teams, fuzzy sets- Qualitative Comparative Analysis.

\section{Introduction}

Buildings in the United States account for 41 percent of total energy consumption and almost 40 percent of $\mathrm{CO}_{2}$ emissions (U.S. Green Building Council, 2016). Designing buildings with higher energy performance requires a "whole system" approach to optimizing everything from architectural programming and systems, to the structural, mechanical, and electrical systems of a building, and can be expanded to include behavioral change at different scales. To achieve this, a highly cross-disciplinary approach is required to consider various passive and active strategies in technical and social domains. This signals the need to shift from traditional sequential design and construction processes toward a more integrated approach. The successful implementation of these integrated processes requires new skills, outlooks, and resources (Kibert, 2016; Yudelson, 2008).

While the industry makes this shift, research has established the value of inter-organizational collaboration to the whole system approach (7 group \& Reed, 2009) and the utility of Building Information Modelling (BIM) to facilitate integrated processes (Krygiel \& Nies, 2008). Many studies have addressed the benefits, risks, and challenges of adopting these new practices(Azhar, 2011; Chien et al., 2014; Ghaffarianhoseini et al., 2017; Kovacic \& Müller, 2014; Seyis, 2019), rendering them as promising approaches to facilitate Whole System Design (WSD). However, the required adaptation of people and processes to the new practices makes it challenging for organizational leaders to take the leap in making such major technical, social, and organizational changes. Moreover, some techniques, if not used within the right context, can have zero or negative 
effect on the outcome (Greckhamer et al., 2008). As organizational scholars argue, effective promotion of change within organizations structure, people, tasks, or technologies requires considering the effects of change on all other components (Cherns, 1976). This can be made feasible by creating typologies of cases in which the effect of the new change on other components can be studied based on the lessons learned from previous cases of the same type (Miller, 1996). Might we also be able to help design and construction project teams strategize for successful implementation of energy goals, by creating successful project types?

To answer this question, we used a novel approach to analyze causal complexities within architectural projects. The analysis revealed three distinct pathways in achieving Highly Energy Efficient (HEE) projects with respect to WSD tools and processes. This enables practitioners to identify the causal pathways that best matches their project settings, and better strategize to incorporate WSD elements that complements their already established processes. Moreover, the novelty of the incorporated approach opens new doors for Architecture, Engineering, and Construction (AEC) researchers to study configurations of project-related processes and organizational structures, revealing new potential strategies to achieve success.

The paper proceeds as follows. The literature review below summarizes past research into the elements of WSD and shows the need for research into the complex causal relationships between WSD elements and HEE building design. After explaining the research method and how we implemented it in this study, we present the research results that show the necessary WSD elements and causal pathways in achieving HEE buildings. Lastly, we will explain implications of our findings, reflect on our study's limitations, and discuss future directions. 


\section{Literature Review: Antecedents of Energy Efficient Building Design}

In order to model pathways to project success, we first review the research on what makes successful whole-system and energy efficient building design. Below we identify 1) contextual, 2) Contractual, 3) social and organizational, and 4) tools and technological factors that scholars have identified as contributing to successful project. We use this literature to identify what elements to test in our later comparative analysis.

\section{Contextual Elements}

We refer to contextual elements as the opportunities and challenges that exist within the environment of project during the design phase that can influence energy efficiency of building projects. These contextual factors include programming factors which include project size, project type and owner type (Molenaar et al., 2014); as well as project complexity which consists of financial, technical and temporal complexities involved with the project (Cicmil \& Marshall, 2005). Research suggests that as project complexity grows, so does the need for a more integrative and whole system approach to address the free exchange of information needed at the early stages of project development (Azari \& Kim, 2016).

Other contextual elements include context readiness which arises from the team capabilities and experiences (Nofera \& Korkmaz, 2010), owners' investment in and strong commitment to the project energy goals and related processes (T. Ahmad \& Aibinu, 2017; Korkmaz, 2007; Krygiel \& Nies, 2008; Pitt et al., 2009b), as well as governmental conditions such as building regulations, taxes and levies, energy efficiency incentives and penalties available (Korkmaz, 2007; Pitt et al., 2009a). 


\section{Contractual Elements}

Due to their complexity, energy efficient buildings face challenges in implementation such as cost overruns and schedule delays. These indicate a greater need for finding the right delivery method that facilitates inter-organizational collaboration (Raouf Ayman M. \& Al-Ghamdi Sami G., 2019). Studies show that contractual settings affect whole-system approach and achievement of project energy efficiency goals in four main ways: 1) selection of a more integrated type of delivery method (single vs. split contracts); 2) timing of involvement of builder and trades (early vs. at the end of the design process); 3) selection of a flexible pricing method (open book vs. close book); and 4) selection of a qualification based procurement method (prequalification vs. open call) (Molenaar et al., 2014); provision of shared incentives; limitation of litigation, liability wavers between key participants, and addressing conflicting obligations in the contract are other ways to facilitate whole-system approach using contracts (I. Ahmad et al., 2019; Robichaud \& Anantatmula, 2011; Thomsen et al., 2009).

\section{Social and Organizational Elements}

Social and organizational elements that contribute to WSD and to achieving energy targets share many techniques and strategies, including facilitating collaborative decision making (Korkmaz, 2007). Collaborative decision-making benefits construction projects in general—and energy efficient buildings, in particular - by removing both physical and incentive-based obstacles to sharing information to improve the building quality (Allen. et al., 2005), by decreasing loss of construction time and resources (MacLeamy, 2004), and by aligning the design and construction teams towards a shared goal (Allen. et al., 2005).

Successful collaborative decision making for achieving energy efficient buildings can be facilitated by six major elements: 
1) Commitment to shared project energy goals(7 group \& Reed, 2009; Dossick \& Neff, 2008; Nofera \& Korkmaz, 2010); 2) Frequent and effective communication (Bechky, 2003; Homayouni et al., 2010; Jarvenpaa \& Leidner, 1999, 1999); 3) performing joint operations and engaging in others' activities through design charrettes, co-location, or other formal and informal communication channels(Ashcraft, 2011; Boland et al., 2007; Jarvenpaa \& Leidner, 1999; Yoo et al., 2006); 4) Performance-led design iteration (7 group \& Reed, 2009; Y. Lu et al., 2020) 5) interpersonal skills and attitudes toward teamwork such as accountability, commitment, fulfillment of mutual obligations, compromising, no-blaming culture, and co-learning attitude (Homayouni et al., 2010; Y. Lu et al., 2020); and 6) fostering trust in data, people, and the collaboration processes (Askay \& Spivack, 2010; Axelrod \& Dion, 1988; Cahill et al., 2003; Jarvenpaa \& Leidner, 1999; Lau \& Rowlinson, 2009; Meyerson et al., 1996).

\section{Tools and Technological elements}

Tools facilitating energy efficient building design include energy or green building rating systems, which can push project teams for more integration, innovation, and sustainable design. Without having a whole-system approach, however, pursuing some credits within such systems might have an actual negative effect on the overall project sustainability goals (Reed \& 7 Group, 2009).

BIM technologies are also important for facilitating team integration and supporting WSD and energy efficient building design (Francom \& Asmar, 2015; Jin et al., 2017). BIM technologies help teams achieve energy efficiency goals through analysis of design and construction decisions that affect energy efficiency (Krygiel \& Nies, 2008; Wong \& Fan, 2013; Zanni et al., 2013), by reducing many risks associated with the uncertainty and complexities of energy efficient systems 
and processes (Azhar et al., 2012; Sacks \& Barak, 2008), and by promoting collaboration and coordination in early stages of design process (Eastman et al., 2011; Mahalingam et al., 2015).

BIM facilitates WSD approach through 1) inclusiveness of all data related to design, manufacturing, construction, commissioning, management and operation of facilities (Harty, 2005; Messner et al., 2006); 2) visual representation of data, facilitating distributed cognition and interpretation of data among team members, organizing and sustaining cross-disciplinary participation, facilitating web-based communication, easing the exploration of opportunities, and enabling designers to informally represent their deliverables with minimal time and effort (Bechky, 2003; Ewenstein \& Whyte, 2009; Harty, 2005; Henderson, 1991; Maher et al., 1996; Whyte et al., 2008); 3) convenience of data retrieval by collecting information from unrelated systems and make it commensurable and coordinated through standardization of formats and processes, facilitating automatic document/data exchange (Harty, 2005); and 4) reliability of data and processes (Allen. et al., 2005).

\section{Complementarities Between HEE Project Elements}

Even though the elements of WSD are all shown to have a positive impact on achieving HEE buildings individually, it is not yet known how this impact changes while they are used with other WSD and contextual project elements. Finding complementarities among these elements can help ensuring that the elements are implemented within the right settings. Within organizational and social science, numerous studies indicate that social and organizational systems can be best studied in configurations, i.e., varying combinations of characteristics that usually occur together (Milgrom \& Roberts, 1995; Miller, 1993, 1996).

This concept is especially effective for studying systemic change. Within AEC industry, implementation of BIM technologies have introduced a technological change, which requires 
alignment of people, structure, processes and culture within related organizations (Tulenheimo, 2015). This alignment (unlike the process of implementing CAD systems) is a disruptive process requiring new organizational systems (Ramilo \& Embi, 2014). As an example, introduction of new BIM technologies may place more workload on informal roles, such as go-to people for information and advice about digital technologies. Combined with other relationships these may create a new informal social network within the organizations(Bonanomi et al., 2019). Implementation of BIM technologies, on the other hand, changes related organizations towards adopting looser and flatter work structures, including more roles of building service and fewer design-related professionals, and changes the collaborative processes towards a more front-end load communication approach (Lu et al., 2020).

Adoption of BIM technologies is also interdependent with the architecture firm size. Studies show that large firms experience fewer challenges compared to small firms. However, the type of challenges that architectural firms face, varies based on their size. The biggest struggles for large organizations tend to be process barriers such as performance of digital tools and disintegration of 3D models to multiple sources, while the greatest barriers in small architectural firms tends to be organizational such as support of staff and managers for digital innovations and willingness to adopt change (Ramilo \& Embi, 2014). After all, adoption of new BIM technologies can enhance organizational effectiveness and organizations can also facilitate adoption of the technology by creating a conducive atmosphere (I. Ahmad et al., 2019; Homayouni et al., 2010).

Formation of trust within team members is also shown to have a complementary relationship with other WSD elements, affecting how team members deal with behavioral and environmental uncertainty (Wang et al., 2019). Control provisions within contracts increase competence-based trust within team members while reducing goodwill-based trust (Malhotra \& Lumineau, 2011). (Wang et al., 2019). Contractual control systems, on the other hand, form a complementary relationship 8| Pag e 
with competence-based trust, while acting as a substitute for the good-will based trust (Wang et al., 2019). There is also a complementary relationship between trust formed after the contract award and term specificity and adaptability of the contract, while contract enforcement and the trust formed afterwards are shown to be substitutes (Yan Ling \& Zhang Lihan, 2020). Trust is also influenced by the level of project complexity raised from external uncertainty, but not the level of organizational and Technical complexity (Lu et al., 2016).

Selection of WSD elements such as project delivery methods, level of team integration, and group cohesion is too affected by project contextual factors.(Leicht et al., 2016; Schaufelberger \& Holm, 2017). Upon selection of the right delivery method, selection of the contractor with characteristics that best match the delivery method, in terms of communication skills, experience with similar project types, ability in financial management, and design capability becomes important for achieving project success (Liu et al., 2016). Arrangement of contracts, in terms of contractual control, coordination, and adaptation is also influenced by contextual factors and plays a role in managing project complexities (Gao et al., 2018). In fact, most contextual and WSD elements within the design process of HP buildings are interdependent, as all such complementary relationships are shown by $\mathrm{Lu}$ et al in a matrix showing co-occurances (Lu et al., 2020).

Yet, researchers have focused little attention on finding the complementarities among multiple contextual and WSD elements, creating typologies of successful energy efficient projects. Closing this research gap is critical, since understanding these causal mechanisms would support successful design of energy-efficient buildings.

\section{Method}

We used fuzzy sets-Qualitative Comparative Analysis (fsQCA) to cluster elements of successful HEE buildings. This method offers a well-developed technique for qualitative and 
holistic comparative analysis among cases allowing the researcher to define variables, called causal conditions in QCA analysis, based on theoretical and substantive knowledge about the cases (Ragin, 2000; Zadeh, 1965). FsQCA method is considered a well-suited method for analyzing causal complexity in social, organizational, and technological aspects of construction projects (Homayouni et al., 2011; Jordan et al., 2011).

In performing fsQCA analysis we look for two main set-relationships: necessity and sufficiency. The necessity test looks for the causal conditions that in almost all cases their membership values are superset of the outcome condition. This means identifying shared causal conditions among cases with a shared outcome. Sufficiency test, on the other hand, is a search for causal conditions or combination of causal conditions that in almost all cases their membership values are subset of the outcome condition. This means examining cases with specific combinations of causal conditions to see if they exhibit the same outcome (Ragin, 2009 pp. 17-25).

Two main measures explain set-relationships in fsQCA analysis both in necessity and sufficiency tests: Consistency and Coverage. Consistency measures the proportion of the cases in the subset that are members of the superset. Thus, the higher the consistency, the stronger the set relationship (Ragin, 2000, p. 113). Schneider and Wagemann (Schneider \& Wagemann, 2012) have recommended using a consistency threshold of 0.9 or above. Coverage, on the other hand, measures the degree in which subset "covers" the superset. In necessity tests, this means how much the causal condition is relevant to the outcome condition. In sufficiency test, this means how much the causal combination accounts for the outcome, leaving room for other causal combinations to cover the outcome. Coverage and consistency sometimes work against each other in social phenomena. Complex causal relationships, involving more causal conditions are more likely to achieve a high consistencies with low coverage (Ragin, 2009 pp. 54-68) 
The steps we took in this work included 1) Defining conditions; conducting a survey and reviewing case studies to Measure the conditions; 2) Calibrating the outcome condition by analyzing the projects' energy efficiency data;3) Calibrating the causal conditions to determine the "necessary" conditions for achieving HEE buildings,; 4) Calibrating the causal conditions for sufficiency tests, entailing examining what elements had to be included in each causal condition, and how they needed to be measured to help create the distinct "causal pathways"; and 5) Constructing the truth table and looking for the causal pathways to successful outcomes: what combinations of elements, clustered together, led to successful HEE projects. These steps are detailed in the sections below.

\section{Defining and Measuring the Causal Conditions}

To define the causal conditions, first, we identified main elements contributing to HEE building design from the research literature as shown in Fig 1. We then designed a survey to measure the extent these elements were implemented in projects with high energy-efficiency goals. For each condition, we asked multiple questions on individual and team levels to ensure we have captured various aspects of the element, to minimize the overall chance of error resulting from misinterpretation of terms, and to have enough information for calibration and recalibration of the fuzzy sets (see below). For instance, to assess the level of Frequent \& Effective Communication, on individual level, we asked if people were effective communicators, and on team level, we asked if there were participatory, well-run, and successful inter-organizational meetings, if communication among different companies were effective, if people could easily get in touch with others from different companies, if there were misunderstandings among them, and finally if they understood the challenges of other companies' scopes (See supplemental materials for the survey questionnaire). 
<Insert Fig 1. about here>

We chose a set of High Performance (HP) projects with awards from the American Institute of Architects/Committee On the Environment (AIA/COTE) as the study population, due to availability of case studies for these projects. This allowed purposive selection of cases to ensure diversity in causal and outcome conditions (Schneider \& Rohlfing, 2016), in addition to providing a context for gaining familiarity with the cases and using the available data for construction and reconstruction of the conditions. We sent the survey to 150 architects associated with 70 projects between 2005 and 2013 and received 33 responses associated with 33 different projects. We reviewed and coded the case studies of these projects for elements related to the projects contextual factors, their approaches to energy efficient building design, and the buildings' energy performance results (See supplemental materials for results of the survey questionnaire as well as the case-study analysis). In Fig. 1 we show how each element in our model derives from survey or case study, and how together with other elements they build various aspects of the main conditions. In addition, we have shown the interdependencies among these conditions with regards to achieving projects' energy efficiency goals as explained in previous section, and based on the authors' empirical knowledge.

\section{Calibrating the Outcome Condition: Buildings' Energy Efficiency}

The next step was calibration of the outcome condition called HEE buildings (set name hee.buildings). Energy efficient buildings may possess various features spanning from single discipline related strategies such as having efficient HVAC systems, LED lighting fixtures, etc. to features requiring inter-disciplinary collaboration such as use of passive energy design strategies, and cross-disciplinary collaboration where creative ideas emerge considering both social and ecological sustainability goals (Stock \& Burton, 2011). 
In this study, however, our focus was only on the resulted energy efficiency of buildings, and thus for calibration of the outcome condition we used the reported values related to energy performance of the study population. However, converting these values to a single value, which represent energy performance of the cases, and is comparable across cases, posed two challenges. First was the inconsistencies within and across energy performance codes and rating systems used to report the energy performances (i.e., mainly the use of operational versus asset ratings and the multiplicity of codes and code updates). Second was comparing building energy efficiency on the basis of total energy consumption, rather than net energy performance, which accounts for energy produced by on-site renewable sources. We tackled these challenges through a series of procedures described by Homayouni (Homayouni, 2015). Ultimately, all reported energy consumption was converted to a number equivalent to Home Energy Rating System (HERS) for residential projects and Zero Energy Performance Index (zEPI) scores for all other building types (New Building Institute, 2018; RESNET, 2019). The fuzzy set intervals were then drawn using natural breaks in these data (Homayouni, 2020a). Table 1 shows the final calibration of the outcome condition for all buildings in the study.

<Insert Table 1. here>

Alternative approaches were considered, including using natural data clusters to perform separate calibrations of buildings using asset ratings rather than operational rating systems. None of the alternatives made a substantial change in the overall conclusions of the study. Based on the presented calibration method, successful HP projects (HEE buildings) are defined as projects with HERS/zEPI scores of 70 or less. Since energy codes and targets are getting more stringent over time, repeating this study for more recent project most likely would translate to choosing a lower cross-over point. 


\section{Calibrating Causal Conditions}

The next step was calibrating data gathered from the survey and case studies for all the elements (Homayouni, 2020b). Given the nature of the award-winning HP projects and the population study of this project, all having reported high values for WSD elements, the survey results were skewed to create a more meaningful set-intervals for the fsQCA analysis. Table 2 shows the final calibration of conditions that were part of either necessity or sufficiency test results.

<Insert Table 2. here>

\section{Necessity Analysis}

Next step was running the necessity test for all the calibrated conditions, one at a time, to find the ones that are shared across all HEE buildings. The following causal conditions appeared as necessary for achieving HEE buildings (with consistency threshold of 0.9): inter-organizational trust, fulfillment of mutual obligations, conducting participatory and successful interorganizational meetings, having easy inter-organizational access and effective communication, close working relationships among architects and engineers, architects involvement in construction processes, overall successful inter-organizational collaboration and having shared goals among participating organizations (Table 3).

<Insert Table 3. here>

The relatively low coverage values in all necessary conditions can be contributed to the trivial nature of the relationship between the outcome and causal conditions. Since all projects in the study population were identified as successful, appearing many of the WSD elements as superset of the outcome, is somewhat trivial. This means that the survey respondents reported high values for the necessary conditions in all buildings (as shown in Table 3), and many of the conditions that 
signal high level of collaboration is most probably required in all projects and not only the HEE buildings.

Reviewing the case-studies also showed all the projects had ambitious energy goals from the outset. Although we did not have enough information about the energy targets to be able to convert them to fuzzy sets, the general availability of such goals needs to be considered in interpreting the sufficiency tests.

\section{Sufficiency Analysis}

One limitation of using QCA methods for running sufficiency analysis is that they restrict the number of conditions that can be tested. Thus, we started the analysis by working on four main conditions of contextual complexity, integration facilitation in contracts, advanced tools, and social and organizational integration (Fig. 1), looking for combinations of conditions that construct a causal pathway in designing HEE projects. We initially defined and calibrated the fuzzy sets for these main conditions, using all relevant factors depicted in Fig. 1. However, we later refined these factors to the conditions depicted in Table 4. based on the following reasons: 1) Removing the necessary conditions; 2) Removing the conditions for which we could not find enough data i.e. performance led design iteration (Such conditions were later considered in finding common themes among the typologies as will be explained in Implications section) 2) Recalibration of the fuzzy sets during the course of going back and forth between theory and examination of cases to bring/remove different dimensions into the sets when the analysis called for it. (Schneider \& Wagemann, 2010) (i.e. removing the "rating systems" from the set of "advanced tools") 3) Dividing the main condition to two separate elements where the contributing

factors did not work in the same direction in constructing the typologies (i.e separating "contract 
pricing method" from the "contract delivery method"); 4) Removing the conditions that were not distributed homogenously over time within the BIM-related factors.

We used Boolean algebra to quantitatively combine the values of constructing elements (showed in Fig. 1) to create the final six main causal conditions (Table 4).

<Insert Table 4. here>

The next step was building the truth table (Ragin, 2009, pp. 23-25). After populating the property space with cases of HP projects, the research team identified the projects with the same combination of causal conditions. Next, the homogeneity of the cases was verified, meaning that, if the cases with the same solution term were not comparable and were not cohere enough to construct a type, the team refined the causal conditions and reconstructed the property space until the cases fit into homogeneous groupings (Ragin, 1999). This procedure also resulted in elimination of three cases from the study, due to underlying conditions that did not align with the rest of the population (i.e. retrofitting as oppose to new construction). Appendix A show the distribution of cases within the truth table, with final conditions and their final calibrated values.

\section{Results: Pathways to HEE Buildings}

As shown in Table 5., three distinct causal pathways to HEE buildings emerged from analysis of the truth-table, considering the consistency threshold of 0.9 . We call these pathways A) Information-Driven, B) Process-Driven, and C) Organization-Driven projects. The set of conditions that we identified in each pathway suggest tangible configurations of factors that work together for achieving successful projects. project leaders may choose to follow these pathways based on contextual conditions of their projects to maximize their chance of achieving success.

<Insert Table 5. Here> 
Each pathway has four INUS conditions, which are described by Mackie (Mackie, 1974) as "Insufficient but Necessary parts of a condition which is itself Unnecessary but Sufficient" for the occurrence of the outcome. This means that INUS conditions are necessary parts of a causal pathway that itself is sufficient but not necessary for achieving the outcome condition. In other words, these elements work together in complex, interdependent ways, even if any one element on its own is not sufficient for achieving the outcome.

\section{Information-Driven Projects}

One pathway to achieving high level of energy efficiency was what we call informationdriven, and we found four INUS conditions that clustered in this pathway. These conditions (as indicated by Table 4 and Table 3) are:

1) Reliable Teams. This indicates that team members from collaborating organizations reliably fulfill their mutual contractual obligations and exceed these obligations to collaborate in an environment of trust.

2) Flexible pricing method. This points towards the continuous involvement of the owner and design team through the construction phase to ensure complete translation of the design ideas, as well as convenience of applying changes to the design throughout the construction. 3) Reliable BIM technology use. This indicates that designers working on projects with BIM have access to, work with, and share 3D+ information cross-organizationally, and they also trust and rely on this information.

4) Inter-organizational scope understanding. This shows that team members develop awareness about other people's scopes of work, including their obstacles and limitations. 
As Table 5 shows, about one-third of cases are explained by this combination of conditions. In all the information-driven cases, the "solution term," or this configuration of factors, was sufficient for reaching HEE buildings.

What is striking here is how BIM implementation and inter-organizational scope understanding are compliments in information-driven pathways. This finding suggests that gaining access to information on the scope of other team members' work through BIM technology is not itself effective unless team members deepen and expand their understanding of the entire project. The case studies on the AIA/COTE projects show that developing this understanding depends on people's openness to learning from and educating one another. This holistic mindset is critical to effective use of the reliable information provided by advanced digital technologies.

Another key finding is that the team dynamics created both using BIM technologies and team members' holistic mindset makes teaming dynamics more complex. This complexity entails a new social and organizational framework for team members' interactions such that contractual obligations among team members is no longer sufficient for projects with ambitious energy targets. In these successful projects, team members "surpassed" their contractual obligations in order to succeed.

\section{Process-Driven Projects}

We named the second causal pathway process-driven. Process-driven projects have the following four INUS conditions: 1) integrated delivery method; 2) flexible pricing method; 3) Reliable Teams; and 4) absence of reliable BIM technology use. This solution term is present in about one quarter of all the projects we studied, and in 94 percent of the process-driven projects, it proved to be sufficient for achieving HEE buildings. 
Process-driven projects set up the right process for organizational integration, which entails using a construction delivery process that facilitates collaboration of the construction and the design team, as well as a flexible pricing method that accrues this collaborative environment. Interestingly, relying on contractual obligation alone does not seem to be enough for achieving HEE projects in this pathway too. These collaborative processes seem to lead to HEE buildings only if team members surpass their contractual obligations to one another. Here, team member attributes such as reliability, and willingness and ability to exceed contractual obligations help in promoting trust in other team members and in the new collaborative processes (see Table 4 and Table 3).

From the work on information-driven projects we found a complementary relationship between r.bim and scope.u conditions in information-driven projects. This complementary relationship remains true in process driven projects as well, and is the key to understanding why r.bim condition has emerged as an INUS condition here: Dropping r.bim from this causal mechanism, would result in the following combination of conditions: i.delivery* f.pricing* mreliable.t. This indicates the following solution term i.delivery*f.pricing* reliable.t* r.bim* scope. $u$ would be a successful pathway to HEE buildings too. But, as shown in the truth table, this cannot be true (See the appendix). In other words, process driven projects do not work well if they do have access to reliable BIM technologies, but without having a whole-system mindset that comes from understanding challenges and obstacles of other peoples' scope of work. They, on the other hand, work perfectly well with presence of both reliable BIM technology use and team members' awareness of others' scope. However, since this later pathway is explained in information driven projects, we define process driven projects strictly as those that do not rely on BIM technologies. 


\section{Organization-Driven Projects}

The third causal pathway in achieving HEE buildings is organization-driven, and it has four INUS conditions: 1) Architectural firm maturity (more than 20 years of experience and more than 50 staff members); 2) Integrated delivery method; 3) Reliable Teams and 4) Absence of reliable BIM technology use. This solution term was present in 40 percent of the studied population, and in 96 percent of organization-driven projects, it was sufficient for achieving high level of energy efficiency.

Well-established architectural firms in this pathway provide the leadership and organizational resources and capacity required for working on new approaches to energy efficient design. In organization-driven projects there is early involvement of the construction team through integrated delivery methods. Again, working with reliable teams who surpass their contractual obligations seems to be an important condition in activating this causal mechanism. This can be linked to the highly collaborative and unconventional process of decision making in process driven projects which requires team members to surpass their contractual obligations and dedicate more time and effort to the decision-making processes.

The interpretation of the absence of "reliable BIM technology use," requires a close attention to the constructs of this condition (bim.design* bim.share* change.m* d.accuracy) and the membership distribution of each construct within the cases. This investigation reveals that most architectural firms in this pathway used BIM tools for internal purposes, and shared their models with the collaborating companies, but relied on traditional contracts to address information exchange liability concerns (indicated by absence of change.m condition). Thus, an alternative hypothesis could be that BIM technologies itself (bim.design* bim.share* d.accuracy) can be implemented with organization-driven projects, but including the liability concerns about BIM 
applications (change.m) seems to not have been worked with this causal mechanism. In other words, including the BIM liability concerns in the contract seems to have been evoking a causal mechanism different from organization driven in which people trust and rely on a well-established architectural firm rather than the terms of the contracts. Further investigation is needed to test this hypothesis.

Another hypothesis could be similar to what we assumed in information driven projects regarding the required co-presence of r.bim and scope.u conditions for achieving HEE projects, since on none of the cases studied did the presence of reliable BIM technology use and scope understanding appeared in lieu of absence of reliable BIM technology use (reliable.t* i.delivery* a.maturity* r.bim* scope.u=HEE.buildings). Further data collection and analysis is needed to test this hypothesis.

\section{Implications: Strategizing to Achieve HEE Buildings}

This study unraveled three different causal pathways for achieving high level of energy efficiency, in addition to revealing the necessary conditions for achieving HEE buildings (Table 3). While the three conditions of architectural firm maturity, flexible pricing method, integration of delivery method, and in many cases reliable BIM technology use are either given or chose based on the projects' direct needs, this study can help project leaders and practitioners in six ways:

1) Implementation of the necessary conditions is recommended for all projects aiming to achieve HEE buildings.

2) In the case of information driven projects, the emphasis needs to be put on strategies that help with inter-organizational scope understanding. Examples include educating the team, holding design charrettes, and co-location. 
3) For companies aiming to implement BIM technologies for the first time, the informationdriven pathway shows the most promise in successful implementation of the technology.

4) In all three typologies working with reliable teams has emerged to be an INUS condition, indicating the importance of exceeding contractual obligations and reliability of project team members.

5) Lessons learned from studying the cases within the three typologies can be followed by project leaders. These lessons, as separately analyzed for each pathway include:

- Information-driven projects: early and extensive use of 3D modeling, design iterations based on energy simulation results, and holding pre-bid conferences addressing energy goals and construction team's responsibilities for achieving those.

- Process-driven projects: adopting strategies that help the team with setting a collaborative process between the design and construction teams. Such strategies include educating the construction team early on, selecting the construction team based on their experience with HP buildings, and using construction teams' experience in adjusting projects' energy goals.

- Organization-driven projects: focusing on architecture firm's leadership skills in providing energy goals for the team, assigning project champions, and educating others.

6) Although inter-organizational trust was emerged as a necessary condition for achieving HEE buildings, we found that the approaches in building and maintaining trust was different in each pathway, requiring attention from project leaders:

- In information driven projects, inter-organizational trust is mostly developed based on team members' trust in the digital information and related work processes. The top strategies to maintain team members trust in this pathway include tailoring contract 
clauses to address BIM related liability issues, developing project specific BIM execution plans, providing technical resources for training staff and providing back-up services for problem resolution.

- In Process driven projects, formation of trust is mostly based on contractual agreements, and their ability to clearly assign tasks and responsibilities, as well as adequately balancing allocation of risks and rewards, so that the team members conflicting obligations to their scopes, projects, and organizations are addressed in the contract. In addition, in this pathway trust can be formed based on prior successful relationships, and therefore strategies such as partnering, and using negotiated procurement methods can be highly effective.

- In Organization driven projects, formation of trust usually starts from people's trust in an already established and successful working relationships within the architectural firm and is maintained through frequent inter-organizational meetings, and pro-active communication at interpersonal and inter-firm levels. Building on prior successful relationship, also plays a major role in in this pathway.

\section{Limitations}

Our research has several limitations. First, while many energy efficient buildings are available to study, we focused only on AIA/COTE winning projects. This means that there may be differences between other energy efficient projects and AIA/COTE projects that we cannot account for in this research design. Second, within the chosen set of AIA-awarded projects, only the projects awarded between 2005 and 2013 were selected, and with the development of BIM technologies we would suggest further analysis going forward. Third, we only studied buildings within the United States, to ensure a baseline for comparing their measures of energy efficiency, and because global 
approaches to teaming and technology would be missed in our data collection strategy. Forth, we surveyed project architects, and as such the results reflect their points of view on the projects. Finally, contacting the project architects only once through the survey and using case-studies for better understanding the projects and refining causal conditions also posed some limitations in working with QCA method, but we tried to compensate for this issue by selection of more cases and relying more on probabilistic rather than deterministic criteria when conducting cross-case analysis as suggested by Ragin (2000 p. 195).

\section{Conclusion \& Future Work}

Designing HEE buildings require optimization of buildings based on many criteria, affecting their energy consumption. Because traditional linear design methods fall short in facilitating such integrated processes, new WSD approaches are emerging. AEC scholars have identified factors that facilitate WSD approaches, but not every project can implement all the techniques at once. Moreover, some techniques, if not used within the right context, can have negative effects on the outcomes. This indicates the need for more studies to find the patterns of complementary factors that influence successful design of HEE buildings.

Scholars working on energy efficient projects have started to focus on bivariate relationships among elements that may facilitate energy efficient design, but no other extensive study to date has been conducted to work on clusters of complementarities to reveal causal pathways that lead to HEE projects. Using an fsQCA approach to analyze complementarities among causal conditions facilitating energy efficient design, we identified the conditions that are necessary for achieving HEE buildings. These include having ambitious and shared energy goals, conducting successful and participatory inter-organizational meetings, close working relationships among architects and engineers, and an overall collaborative decision-making environment. 
More importantly we show how there are three distinct causal pathways for designing HEE buildings: information-driven, process-driven, and organization-driven. Although, validation of the three types of projects we identified here will require future work, this study set forth a direction for pursuing similar studies on working with causal complexities within AEC projects.

For practitioners, our research suggests that project leaders may be able to better strategize in positioning their projects among different styles or approaches to teaming, technology choices, and building and maintaining trust based on their project's contextual settings and limitations. This study is novel in that it systematically examined what combinations of technology and teaming work best together, as evidenced by successful projects. Practitioners would do well to take note of the suggested strategies that we show work well in each once they positioned their projects as information-driven, process-driven or organization-driven.

Future studies may build upon this work by studying more recent projects, discussing the results with other practitioners to verify the proposed typologies, and by studying the relationship between BIM implementation and team members' understanding of others' scope of work on process driven and organization driven projects. We suggest that studying how projects followor deviate from - information-driven, process-driven, or organization-driven pathways would give insight on how organizations develop new strategies for achieving ambitious energy efficiency goals.

\section{Appendix}

Table 6 demonstrates the observed cases in the truth table as well as the rows that were used for counter intuitive and counterfactual tests as referred to in the paper.

<Insert Table 6 here> 


\section{Data Availability Statement}

Some or all data, models, or code generated or used during the study are available in a repository or online in accordance with funder data retention policies. (The American Institute of Architects. 2020. "AIA Committee on the Environment Top Ten Projects." https://www.aiatopten.org/ (May 7, 2020); Homayouni, H. (2020a). "AIA-COTE-TOP-10-datacompilation." $\quad$ https://osf.io/7qcjx/?view_only=3614423b7b6e4a4b9b1560e6c9222dc2; Homayouni, H. HSD-Elements-Questionnaire-Survey." https://osf.io/kqpza/?view_only=3fc2b52918b34191937362669f631b33)

Some or all data, models, or code generated or used during the study are proprietary or confidential in nature and may only be provided with restrictions (e.g. anonymized data)(identified survey results).

All data, models, and code generated or used during the study appear in the submitted article.

\section{Acknowledgments}

This material is based upon work supported by the National Science Foundation under Grant No. 0823338 “Assessing Collaboration Across Organizational Boundaries in U.S. Green Construction: Does working together with new information technology result in better buildings?" Conducting the survey was approved by an International Review Board (IRB) at the University of Washington, Seattle, USA.

We would like to thank the anonymous referees of JME journal who have carefully reviewed our manuscript for their constructive and insightful comments.

\section{Supplemental Materials}

The questionnaire survey is available online in OSF library (https://osf.io/kqpza/?view_only=3fc2b52918b34191937362669f631b33). 


\section{References}

7 group, \& Reed, B. (2009). The Integrative Design Guide to Green Building: Redefining the Practice of Sustainability. Wiley.Com.

Ahmad, I., Azhar, N., \& Chowdhury, A. (2019). Enhancement of IPD Characteristics as Impelled by Information and Communication Technology. Journal of Management in Engineering, 35(1), 04018055. https://doi.org/10.1061/(ASCE)ME.1943-5479.0000670

Ahmad, T., \& Aibinu, A. A. (2017). Project delivery attributes influencing green building project outcomes. Built Environment Project and Asset Management, 7(5), 471-489. https://doi.org/10.1108/BEPAM-11-2016-0066

Allen., R. K., Becerik, B., Pollalis, S. N., \& Schwegler, B. R. (2005). Promise and Barriers to Technology Enabled and Open Project Team Collaboration. Journal of Professional Issues in Engineering Education and Practice, 131(4), 301-311. https://doi.org/10.1061/(ASCE)10523928(2005)131:4(301)

Ashcraft, H. W. (2011). IPD teams: Creation, Organization and Management. San Francisco: Hanson Bridgett LLP.

Askay, D. A., \& Spivack, A. J. (2010). The Multidimensional Role of Trust in Enabling Creativity within Virtual Communities of Practice: A Theoretical Model Integrating Swift, Knowledge-Based, Institution-Based, and Organizational Trust. 2010 43rd Hawaii International Conference on System Sciences, 1-10. https://doi.org/10.1109/HICSS.2010.389

Axelrod, R., \& Dion, D. (1988). The Further Evolution of Cooperation. Science, 242(4884), 1385-1390. https://doi.org/10.1126/science.242.4884.1385

Azari, R., \& Kim, Y.-W. (2016). Integration Evaluation Framework for Integrated Design Teams of Green Buildings: Development and Validation. Journal of Management in Engineering, 32(3), 04015053. https://doi.org/10.1061/(ASCE)ME.1943-5479.0000416 
Azhar, S. (2011). Building Information Modeling (BIM): Trends, Benefits, Risks, and Challenges for the AEC Industry. Leadership and Management in Engineering, 11(3), 241-252. https://doi.org/10.1061/(ASCE)LM.1943-5630.0000127

Azhar, S., Khalfan, M., \& Maqsood, T. (2012). Building Information Modelling (BIM): Now and beyond. Construction Economics and Building, 12(4), 15-28. https://doi.org/10.5130/AJCEB.v12i4.3032

Bechky, B. A. (2003). Sharing Meaning Across Occupational Communities: The Transformation of Understanding on a Production Floor. Organization Science, 14(3), 312-330. https://doi.org/10.1287/orsc.14.3.312.15162

Boland, R. J., Lyytinen, K., \& Yoo, Y. (2007). Wakes of Innovation in Project Networks: The Case of Digital 3-D Representations in Architecture, Engineering, and Construction. Organization Science, 18(4), 631-647. https://doi.org/10.1287/orsc.1070.0304

Bonanomi, M. M., Hall, D. M., Staub-French, S., Tucker, A., \& Talamo, C. M. L. (2019). The impact of digital transformation on formal and informal organizational structures of large architecture and engineering firms. Engineering, Construction and Architectural Management, 27(4), 872-892. https://doi.org/10.1108/ECAM-03-2019-0119

Cahill, V., Gray, E., Seigneur, J.-M., Jensen, C. D., Chen, Y., Shand, B., Dimmock, N., Twigg, A., Bacon, J., \& English, C. (2003). Using trust for secure collaboration in uncertain environments. IEEE Pervasive Computing, 2(3), 52-61. https://doi.org/10.1109/MPRV.2003.1228527

Cherns, A. (1976). The principles of sociotechnical design. Human Relations, 29(8), 783-792.

Chien, K.-F., Wu, Z.-H., \& Huang, S.-C. (2014). Identifying and assessing critical risk factors for BIM projects: Empirical study. Automation in Construction, 45, 1-15. https://doi.org/10.1016/j.autcon.2014.04.012 
Cicmil, S., \& Marshall, D. (2005). Insights into collaboration at the project level: Complexity, social interaction and procurement mechanisms. Building Research \& Information, 33(6), 523-535. https://doi.org/10.1080/09613210500288886

Dossick, C. S., \& Neff, G. (2008). How leadership overcomes organizational divisions in BIM-enabled commercial construction. LEAD, 13. http://ww.academiceventplanner.com/Dossick_Neff.pdf

Eastman, C., Teicholz, P., Sacks, R., \& Liston, K. (2011). BIM handbook: A guide to building information modeling for owners, managers, designers, engineers and contractors. John Wiley \& Sons.

Ewenstein, B., \& Whyte, J. (2009). Knowledge Practices in Design: The Role of Visual Representations as 'Epistemic Objects'. Organization Studies, 30(1), 07-30. https://doi.org/10.1177/0170840608083014

Francom, T. C., \& Asmar, M. (2015). Project quality and change performance differences associated with the use of Building Information Modeling in design and construction projects: Univariate and multivariate analyses. Journal of Construction Engineering and Management, 141(9), 04015028. https://doi.org/10.1061/(ASCE)C0.1943-7862.0000992

Gao, N., Chen, Y., Wang, W., \& Hong, Y. (2018). Addressing Project Complexity: The Role of Contractual Functions. Journal of Management in Engineering, 34(3), 04018011. https://doi.org/10.1061/(ASCE)ME.1943-5479.0000613

Ghaffarianhoseini, A., Tookey, J., Ghaffarianhoseini, A., Naismith, N., Azhar, S., Efimova, O., \& Raahemifar, K. (2017). Building Information Modelling (BIM) uptake: Clear benefits, understanding its implementation, risks and challenges. Renewable and Sustainable Energy Reviews, 75, 1046-1053. https://doi.org/10.1016/j.rser.2016.11.083

Greckhamer, T., Misangyi, V. F., Elms, H., \& Lacey, R. (2008). Using qualitative comparative analysis in strategic management research: An examination of combinations of industry, corporate, and business-unit effects. Organizational Research Methods, 11(4), 695-726. 
Harty, C. (2005). Innovation in construction: A sociology of technology approach. Building Research \& Information, 33(6), 512-522. https://doi.org/10.1080/09613210500288605

Henderson, K. (1991). Flexible Sketches and Inflexible Data Bases: Visual Communication, Conscription Devices, and Boundary Objects in Design Engineering. Science, Technology, \& Human Values, 16(4), 448-473. https://doi.org/10.1177/016224399101600402

Homayouni, H. (2015). Aligning Contractual, Technological, and Organizational Elements to Achieve Higher Performance buildings: A Qualitative Comparative Analysis Approach.

http://hdl.handle.net/1773/33622

Homayouni, H. (2020a). AIA-COTE-TOP-10-data-compilation.

https://osf.io/7qcjx/?view_only=3614423b7b6e4a4b9b1560e6c9222dc2

Homayouni, H. (2020b). WSD-Elements-Questionnaire-Survey.

https://osf.io/kqpza/?view_only=3fc2b52918b34191937362669f631b33

Homayouni, H., Dossick, C. S., \& Neff, G. (2011). Construction Projects as Fuzzy-Sets: A Set Theoretic Approach to Analysing the Role of Building Information Modelling in Higher Performance Buildings. Proceedings Editor.

Homayouni, H., Neff, G., \& Dossick, C. S. (2010). Theoretical Categories of Successful Collaboration and BIM Implementation within the AEC Industry. Construction Research Congress, 778-788. https://doi.org/10.1061/41109(373)78

Jarvenpaa, S. L., \& Leidner, D. E. (1999). Communication and Trust in Global Virtual Teams. Organization Science, 10(6), 791-815. https://doi.org/10.1287/orsc.10.6.791

Jin, R., Hancock, C. M., Tang, L., \& Wanatowski, D. (2017). BIM Investment, Returns, and Risks in China's AEC Industries. Journal of Construction Engineering and Management, 143(12), 04017089. https://doi.org/10.1061/(ASCE)C0.1943-7862.0001408 
Jordan, E., Gross, M., Javernick-Will, A., \& Garvin, M. (2011). Use and misuse of qualitative comparative analysis. Construction Management and Economics, 29, 1159-1173. https://doi.org/10.1080/01446193.2011.640339

Kibert, C. J. (2016). Sustainable Construction: Green Building Design and Delivery. John Wiley \& Sons. Korkmaz, S. (2007). Piloting evaluation metrics for high performance green building project delivery. https://etda.libraries.psu.edu/catalog/8089

Kovacic, I., \& Müller, C. (2014). Challenges for the implementation of integrated design in the planning practice. Procedia - Social and Behavioral Sciences, 119, 529-538. https://doi.org/10.1016/j.sbspro.2014.03.059

Krygiel, E., \& Nies, B. (2008). Green BIM: Successful Sustainable Design with Building Information Modeling. John Wiley \& Sons.

Lau, E., \& Rowlinson, S. (2009). Interpersonal trust and inter-firm trust in construction projects. Construction Management and Economics, 27(6), 539-554.

Leicht, R. M., Molenaar, K. R., Messner, J. I., Franz, B. W., \& Esmaeili, B. (2016). Maximizing success in integrated projects: An owner's guide. Version.

Liu, B., Huo, T., Meng, J., Gong, J., Shen, Q., \& Sun, T. (2016). Identification of key contractor characteristic factors that affect project success under different project delivery systems: Empirical analysis based on a group of data from China. Journal of Management in Engineering, 32(1), 05015003. https://doi.org/10.1061/(ASCE)ME.1943-5479.0000388

Lu, P., Qian, L., Chu, Z., \& Xu, X. (2016). Role of Opportunism and Trust in Construction Projects: Empirical Evidence from China. Journal of Management in Engineering, 32(2), 05015007. https://doi.org/10.1061/(ASCE)ME.1943-5479.0000401 
Lu, Y., Sood, T., Chang, R., \& Liao, L. (2020). Factors impacting integrated design process of net zero energy buildings: An integrated framework. International Journal of Construction Management, 1-13. https://doi.org/10.1080/15623599.2020.1742625

Mackie, J. L. (1974). The Cement of the Universe: A Study of Causation. Clarendon Press.

MacLeamy, P. (2004). Collaboration, integrated information and the project lifecycle in building design, construction and operation. WP-1202, The Construction Users Roundtable.

Mahalingam, A., Yadav, A. K., \& Varaprasad, J. (2015). Investigating the Role of Lean Practices in Enabling BIM Adoption: Evidence from Two Indian Cases. Journal of Construction Engineering and Management, 141(7), 05015006. https://doi.org/10.1061/(ASCE)CO.1943-7862.0000982

Maher, M. L., Cicognani, A., \& Simoff, S. (1996). An experimental study of computer mediated collaborative design. Proceedings of WET ICE '96. IEEE 5th Workshop on Enabling Technologies; Infrastucture for Collaborative Enterprises, 268-273. https://doi.org/10.1109/ENABL.1996.555233

Malhotra, D., \& Lumineau, F. (2011). Trust and Collaboration in the Aftermath of Conflict: The Effects of Contract Structure. Academy of Management Journal, 54(5), 981-998. https://doi.org/10.5465/amj.2009.0683

Messner, J., David, R. R., \& Moeck, M. (2006). Virtual facility prototyping for sustainable project delivery. Electronic Journal of Information Technology in Construction, 11, 723-738. http://www.scopus.com/inward/citedby.url?scp=33750240490\&partnerID=8YFLogxK Meyerson, D., Weick, K. E., \& Kramer, R. M. (1996). Swift trust and temporary groups. Trust in Organizations: Frontiers of Theory and Research, 166, 195.

Milgrom, P., \& Roberts, J. (1995). Complementarities and fit strategy, structure, and organizational change in manufacturing. Journal of Accounting and Economics, 19(2), 179-208. https://doi.org/10.1016/0165-4101(94)00382-F 
Miller, D. (1993). The Architecture of Simplicity. Academy of Management Review. https://doi.org/10.5465/amr.1993.3997509

Miller, D. (1996). Configurations Revisited. Strategic Management Journal, 17(7), 505-512. https://doi.org/10.1002/(SICI)1097-0266(199607)17:7<505::AID-SMJ852>3.0.CO;2-I

Molenaar, K., Messner, J., Leicht, R., Franz, B., \& Esmaeili, B. (2014). Examining the role of integration in the success of building construction projects. Charles Pankow Foundation/Construction Industry Institute Austin, TX.

New Building Institute. (2018). Zero Energy Performance Index (zEPI) and zEPI Jurisdictional Scores. New Buildings Institute. https://newbuildings.org/resource/zepi-zero-energy-performance-index/ Nofera, W., \& Korkmaz, S. (2010). Design process integration for sustainable, high performance buildings. Proceedings Editors.

Pitt, M., Tucker, M., Riley, M., \& Longden, J. (2009a). Towards sustainable construction: Promotion and best practices. Construction Innovation, 9(2), 201-224.

Pitt, M., Tucker, M., Riley, M., \& Longden, J. (2009b). Towards sustainable construction: Promotion and best practices. Construction Innovation, 9(2), 201-224. https://doi.org/10.1108/14714170910950830

Ragin, C. C. (1999). Using qualitative comparative analysis to study causal complexity. Health Services Research, 34(5 Pt 2), 1225-1239. https://www.ncbi.nlm.nih.gov/pmc/articles/PMC1089061/ Ragin, C. C. (2000). Fuzzy-Set Social Science. University of Chicago Press.

Ragin, C. C. (2009). Redesigning social inquiry: Fuzzy sets and beyond. University of Chicago Press.

Ramilo, R., \& Embi, M. R. B. (2014). Critical analysis of key determinants and barriers to digital innovation adoption among architectural organizations. Frontiers of Architectural Research, 3(4), 431-451. https://doi.org/10.1016/j.foar.2014.06.005 
Raouf Ayman M., \& Al-Ghamdi Sami G. (2019). Effectiveness of Project Delivery Systems in Executing Green Buildings. Journal of Construction Engineering and Management, 145(10), 03119005. https://doi.org/10.1061/(ASCE)C0.1943-7862.0001688

Reed, B., \& 7 Group. (2009). The integrative design guide to green building: Redefining the practice of sustainability (Vol. 43). John Wiley \& Sons. http://books.google.com/books?hl=en\&lr=\&id=GUpyUI010gQC\&oi=fnd\&pg=PR11\&dq=the+integ rative+design+guide+to+green+building\&ots=2KCK472ING\&sig=JJ8IIvQWsbarGCz1yww6OJg3OLE RESNET. (2019). HERS Raters. RESNET. https://www.resnet.us/raters/hers-raters/

Robichaud, L. B., \& Anantatmula, V. S. (2011). Greening project management practices for sustainable construction. Journal of Management in Engineering, 27(1), 48-57. https://doi.org/10.1061/(ASCE)ME.1943-5479.0000030

Sacks, R., \& Barak, R. (2008). Impact of three-dimensional parametric modeling of buildings on productivity in structural engineering practice. Automation in Construction, 17(4), 439-449.

Schaufelberger, J. E., \& Holm, L. (2017). Management of construction projects: A constructor's perspective. Taylor \& Francis.

Schneider, C. Q., \& Rohlfing, I. (2016). Case Studies Nested in Fuzzy-set QCA on Sufficiency: Formalizing Case Selection and Causal Inference. Sociological Methods \& Research, 45(3), 526-568. https://doi.org/10.1177/0049124114532446

Schneider, C. Q., \& Wagemann, C. (2010). Standards of Good Practice in Qualitative Comparative Analysis (QCA) and Fuzzy-Sets. Comparative Sociology, 9(3), 397-418.

https://doi.org/10.1163/156913210X12493538729793

Schneider, C. Q., \& Wagemann, C. (2012). Set-theoretic methods for the social sciences: A guide to qualitative comparative analysis. Cambridge University Press. 
Seyis, S. (2019). Pros and Cons of Using Building Information Modeling in the AEC Industry. Journal of Construction Engineering and Management, 145(8), 04019046. https://doi.org/10.1061/(ASCE)C0.1943-7862.0001681

Stock, P., \& Burton, R. J. F. (2011). Defining Terms for Integrated (Multi-Inter-Trans-Disciplinary) Sustainability Research. Sustainability, 3(8), 1090-1113. https://doi.org/10.3390/su3081090

Thomsen, C., Darrington, J., Dunne, D., \& Lichtig, W. (2009). Managing integrated project delivery. Construction Management Association of America (CMAA), McLean, VA, 105.

Tulenheimo, R. (2015). Challenges of implementing new technologies in the world of BIM-Case study from construction engineering industry in Finland. Procedia Economics and Finance, 21(Henttinen).

U.S. Green Building Council. (2016). Benefits of Green Building / U.S. Green Building Council. https://www.usgbc.org/articles/green-building-facts

Wang, D., Fu, H., \& Fang, S. (2019). The efficacy of trust for the governance of uncertainty and opportunism in megaprojects: The moderating role of contractual control. Engineering, Construction and Architectural Management, 27(1), 150-167. https://doi.org/10.1108/ECAM-092018-0409

Whyte, J., Ewenstein, B., Hales, M., \& Tidd, J. (2008). Visualizing Knowledge in Project-Based Work. Long Range Planning, 41(1), 74-92. https://doi.org/10.1016/j.Irp.2007.10.006

Wong, K., \& Fan, Q. (2013). Building information modelling (BIM) for sustainable building design. Facilities, 31(3/4), 138-157.

Yan Ling, \& Zhang Lihan. (2020). Interplay of Contractual Governance and Trust in Improving Construction Project Performance: Dynamic Perspective. Journal of Management in Engineering, 36(4), 04020029. https://doi.org/10.1061/(ASCE)ME.1943-5479.0000791 
Yoo, Y., Boland, R. J., \& Lyytinen, K. (2006). From Organization Design to Organization Designing.

Organization Science, 17(2), 215-229. https://doi.org/10.1287/orsc.1050.0168

Yudelson, J. (2008). Green Building Through Integrated Design greensource Books. McGraw Hill Professional.

Zadeh, L. A. (1965). Fuzzy sets. Information and Control, 8(3), 338-353.

Zanni, M. A., Soetanto, R., \& Ruikar, K. (2013). Exploring the potential of BIM-integrated sustainability assessment in AEC. Sustainable Building Conference 2013.

Fig. 1. Elements affecting buildings' energy efficiency design, their inter-relationships, and associated method of data collection.

Table 1. Calibration of the outcome condition

\begin{tabular}{cccc}
$\begin{array}{c}\text { Membership in the set of } \\
\text { "hee.buildings" }\end{array}$ & $\begin{array}{c}\text { Final HERS/ zEPI } \\
\text { Scores }\end{array}$ & $\begin{array}{c}\text { Membership score in } \\
\text { "hee.buildings" set }\end{array}$ & $\begin{array}{c}\text { Number of } \\
\text { Cases }\end{array}$ \\
\hline Completely in the set & $19-55$ & 1 & 7 \\
More in than out of the set & $58-70$ & 0.67 & 14 \\
More out than in the set & $82-86$ & 0.33 & 2 \\
Completely out of the set & $90-105$ & 0 & 8
\end{tabular}


Table 2. Calibrating raw data

\begin{tabular}{|c|c|c|c|}
\hline Causal Conditions & Set name & \multicolumn{2}{|c|}{ Set Intervals \& Membership Scores } \\
\hline $\begin{array}{l}\text { Integration Level of Delivery } \\
\text { Method }\end{array}$ & i.delivery & \multicolumn{2}{|c|}{$\begin{array}{c}\text { Design Bid Build: 0; Design Bid Build with a CM and } \\
\text { multiple prime contracts: 0.2; Invited Bid: 0.30; Federal } \\
\text { government small business set aside/ Negotiated Bid: } \\
\text { 0.4; CM@ Risk: 0.7; Design Build: 0.9; Modified } \\
\text { IPD/Negotiated Contract: } 1\end{array}$} \\
\hline $\begin{array}{l}\text { Flexibility of Contract Pricing } \\
\text { Method }\end{array}$ & f.pricing & \multicolumn{2}{|c|}{ Lump Sum: 0; GMP: 0.9; Cost Plus: 1} \\
\hline Inter-Organizational Collaboration & i.colab & \multicolumn{2}{|c|}{$\begin{array}{c}\text { Very Successful:1; Somewhat Successful: 0.67; } \\
\text { Neutral:0.33; Very Unsuccessful-Somewhat } \\
\text { Unsuccessful:0 }\end{array}$} \\
\hline Shared Goals & s.goals & \multicolumn{2}{|c|}{$\begin{array}{c}\text { People sharing similar goals for the project: Completely } \\
\text { agree:1; Mostly agree: } 0.67 \text {; Neutral: } 0.33 \text {; Mostly \& } \\
\text { Completely disagree: } 0\end{array}$} \\
\hline $\begin{array}{c}\text { Participatory Inter-Organizational } \\
\text { Meetings }\end{array}$ & p.meetings & \multicolumn{2}{|l|}{$\begin{array}{l}\text { Participatory meetings among } \\
\text { different companies }\end{array}$} \\
\hline $\begin{array}{l}\text { Successful Inter-Organizational } \\
\text { Meetings }\end{array}$ & s.meetings & \multicolumn{2}{|l|}{ Successful meetings among companies } \\
\hline Reliability of Project Team Members & t.reliability & \multicolumn{2}{|l|}{ Project team members being reliable } \\
\hline $\begin{array}{l}\text { Effective Communications among } \\
\text { Partner Companies }\end{array}$ & e.com & \multicolumn{2}{|l|}{$\begin{array}{l}\text { Communications among partner } \\
\text { companies being effective }\end{array}$} \\
\hline Easy Inter-Organizational Access & i.access & $\begin{array}{l}\text { Getting in touch with other companies } \\
\text { without problem }\end{array}$ & \multirow{4}{*}{$\begin{array}{l}\text { Always: } 1 \text {; } \\
\text { Usually: } 0.67 ; \\
\text { Sometimes: } \\
\text { 0.33; } \\
\text { Never- } \\
\text { Seldom: } 0\end{array}$} \\
\hline $\begin{array}{l}\text { Architects \& Engineers Close } \\
\text { Working Relationships }\end{array}$ & ae.close & Engineers work closely with architects & \\
\hline Inter-Organizational Trust & Trust.o & Trust other companies' actions & \\
\hline $\begin{array}{l}\text { Inter-Organizational Scope } \\
\text { Understanding }\end{array}$ & scope.u & $\begin{array}{l}\text { Understanding challenges and } \\
\text { obstacles of other companies' scope }\end{array}$ & \\
\hline Fulfillment of Mutual Obligations & mutuality & \multicolumn{2}{|l|}{$\begin{array}{l}\text { Fulfilled mutual obligations among } \\
\text { partnering companies }\end{array}$} \\
\hline Exceeding Contractual Obligations & contract.e & \multicolumn{2}{|l|}{$\begin{array}{l}\text { Collaborating companies exceeding } \\
\text { the minimum contractual obligations }\end{array}$} \\
\hline Team Members Trust in Digital Data & d.accuracy & \multicolumn{2}{|l|}{$\begin{array}{l}\text { Team members' trusting information } \\
\text { in shared electronic documents }\end{array}$} \\
\hline $\begin{array}{l}\text { Sharing Digital Information Across } \\
\text { Organizations }\end{array}$ & bim.share & \multicolumn{2}{|c|}{$\begin{array}{c}\text { Shared across companies: } 1 \text {; In house only: } 0.33 \text {; There } \\
\text { were no digital files: } 0\end{array}$} \\
\hline \multicolumn{4}{|l|}{ Inclusion of Liability Concerns } \\
\hline $\begin{array}{l}\text { Across Companies Within } \\
\text { Contractual Agreements }\end{array}$ & Change.m & \multicolumn{2}{|c|}{ Yes:1; Partly/ I don't know: 0.33; No: 0} \\
\hline $\begin{array}{l}\text { Digital 3D+ Representation of data } \\
\text { During the DD Phase }\end{array}$ & bim.design & \multicolumn{2}{|l|}{ Used:1; Not-used: 0} \\
\hline $\begin{array}{l}\text { Architectural Firm's Number of } \\
\text { Employees }\end{array}$ & a.number & \multicolumn{2}{|c|}{$\begin{array}{c}\text { 0-10 people: } 0 ; 11-20 \text { people:0.33; } 21-50 \text { people: } 0.67 \text {; } \\
51+\text { people:1 }\end{array}$} \\
\hline $\begin{array}{l}\text { Architectural Firm's Age at the Time } \\
\text { of Project Completion }\end{array}$ & a.age & \multicolumn{2}{|c|}{$\begin{array}{c}1-10 \text { years: } 0 ; 11-20 \text { years: } 0.33 ; 21-30 \text { years: } 0.67 ; \\
31+\text { years: } 1\end{array}$} \\
\hline
\end{tabular}


Table 3. Necessary conditions for achieving HEE buildings

\begin{tabular}{cccc} 
Necessary Conditions & Set Name & Consistency & Coverage \\
\hline Inter-Organizational Trust & Trust.o & 0.941176 & 0.643287 \\
Fulfillment of Mutual Obligations & mutuality & 0.944118 & 0.642257 \\
Participatory Inter-Organizational & p.meetings & 0.970000 & 0.583924 \\
Meetings & & 0.946471 & 0.631476 \\
Successful Inter-Organizational Meetings & s.meetings & 0.925882 & 0.650145 \\
Effective Communications & e.com & 0.931765 & 0.621908 \\
Easy Inter-Organizational Access & i.access & 0.961176 & 0.617069 \\
Architects \& Engineers Close Working & ae.close & 0.982353 & 0.59136 \\
Relationships & i.colab & 0.941176 & 0.640000 \\
Inter-Organizational Collaboration & s.goals & &
\end{tabular}

Table 4. Coding scheme for calibration of the causal conditions used for sufficiency analysis

\begin{tabular}{|c|c|c|}
\hline Conditions & Set Name & Calibration Mechanism (Boolean functions) \\
\hline Architectural Firm Maturity & a.maturity & a.number*a.age \\
\hline Flexible Pricing Method & f.pricing & \\
\hline $\begin{array}{c}\text { Inter-Organizational Scope } \\
\text { Understanding }\end{array}$ & scope.u & \\
\hline Reliable Team & reliable.t & contract.e* t.reliability \\
\hline Reliable BIM Technology Use & r.bim & bim.design* bim.share* change.m* d.accuracy \\
\hline Integration of Delivery Method & i.delivery & \\
\hline
\end{tabular}

Table 5. Solution terms with coverage and consistency values

\begin{tabular}{crrrr} 
Type & Solution Terms & \multicolumn{1}{l}{$\begin{array}{l}\text { Raw } \\
\text { Coverage }\end{array}$} & $\begin{array}{l}\text { Unique } \\
\text { Coverage }\end{array}$ & Consistency \\
\hline A & r.bim*scope.u* reliable.t ${ }^{*}$ f.pricing & 0.301525 & 0.178430 & 1.000000 \\
B & i.delivery*f.pricing* reliable.t* r.bim & 0.267081 & 0.076228 & 0.934783 \\
C & a.maturity* i.delivery* reliable.t* r.bim & 0.398645 & 0.188594 & 0.955345 \\
& Total & 0.671937 & - & 0.973017
\end{tabular}


Table 6. The truth table

\begin{tabular}{|c|c|c|c|c|c|c|c|c|c|c|}
\hline 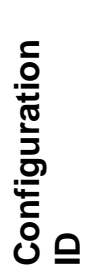 & 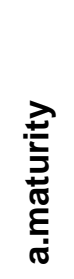 & $\frac{\text { E }}{\underline{\underline{I}}}$ & 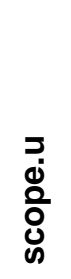 & 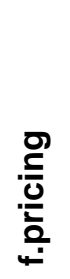 & 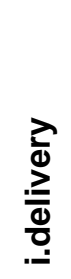 & $\begin{array}{l}\overrightarrow{0} \\
\frac{0}{0} \\
\frac{\sigma}{0} \\
\underline{0}\end{array}$ & 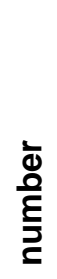 & 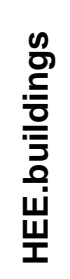 & 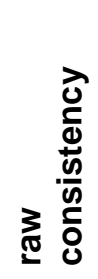 & Typology \\
\hline 1 & 0 & 1 & 1 & 1 & 1 & 1 & 3 & 1 & 1.00 & Type A \\
\hline 2 & 1 & 0 & 0 & 0 & 1 & 1 & 3 & 1 & 0.97 & Type C \\
\hline 3 & 1 & 0 & 1 & 1 & 1 & 1 & 2 & 1 & 0.92 & Type B \& C \\
\hline 4 & 1 & 0 & 0 & 0 & 0 & 0 & 2 & 0 & 0.51 & Type A - Counter intuitive \\
\hline 5 & 0 & 1 & 1 & 1 & 0 & 1 & 2 & 1 & 1.00 & Type A \\
\hline 6 & 0 & 0 & 1 & 1 & 1 & 1 & 2 & 1 & 0.92 & Type B \\
\hline 7 & 0 & 0 & 1 & 1 & 1 & 0 & 2 & 0 & 0.81 & - \\
\hline 8 & 0 & 0 & 1 & 0 & 0 & 1 & 2 & 0 & 0.39 & - \\
\hline 9 & 0 & 0 & 1 & 1 & 0 & 0 & 2 & - & 0.96 & Undetermined \\
\hline 10 & 1 & 1 & 1 & 1 & 1 & 1 & 1 & 1 & 1.00 & Type A \\
\hline 11 & 1 & 1 & 0 & 1 & 1 & 0 & 1 & - & 1.00 & Undetermined \\
\hline 12 & 1 & 0 & 1 & 1 & 1 & 0 & 1 & - & 0.91 & Undetermined \\
\hline 13 & 1 & 0 & 1 & 0 & 1 & 1 & 1 & 1 & 0.97 & Type C \\
\hline 14 & 1 & 0 & 1 & 0 & 0 & 1 & 1 & 0 & 0.60 & - \\
\hline 15 & 0 & 1 & 1 & 0 & 0 & 1 & 1 & 0 & 0.67 & - \\
\hline 16 & 0 & 1 & 0 & 0 & 0 & 0 & 1 & 0 & 0.45 & Type B \& C- Counter-intuitive \\
\hline 17 & 0 & 0 & 1 & 0 & 1 & 0 & 1 & 0 & 0.83 & - \\
\hline 18 & 0 & 0 & 1 & 0 & 0 & 0 & 1 & 0 & 0.44 & Type B- Counter-intuitive \\
\hline 19 & 0 & 0 & 0 & 1 & 1 & 1 & 1 & 1 & 0.91 & Type B \\
\hline 23 & 1 & 1 & 1 & 1 & 0 & 1 & 0 & 1 & - & Type A- Counter-fact \\
\hline 28 & 1 & 1 & 1 & 0 & 0 & 0 & 0 & 0 & - & Type B- Counter-intuitive counter-fact \\
\hline 29 & 1 & 1 & 0 & 1 & 1 & 1 & 0 & 1 & - & Type B counter-fact \\
\hline 34 & 1 & 1 & 0 & 0 & 0 & 0 & 0 & 0 & - & Type B- Counter-intuitive counter-fact \\
\hline 38 & 1 & 0 & 1 & 0 & 0 & 0 & 0 & - & - & Type B- Counter-intuitive counter-fact \\
\hline 39 & 1 & 0 & 0 & 1 & 1 & 1 & 0 & 1 & - & Type C- Counter-fact \\
\hline 43 & 1 & 0 & 0 & 0 & 1 & 0 & 0 & - & - & Type A-Counter-intuitive counter-fact \\
\hline 46 & 0 & 1 & 1 & 1 & 0 & 0 & 0 & 0 & - & Type C - Counter-intuitive counter-fact \\
\hline 49 & 0 & 1 & 1 & 0 & 0 & 0 & 0 & - & - & Type B- Counter-intuitive counter-fact \\
\hline 50 & 0 & 1 & 0 & 1 & 1 & 1 & 0 & 1 & - & Type B- counter-fact \\
\hline 53 & 0 & 1 & 0 & 1 & 0 & 0 & 0 & 0 & - & Type C-Counter-intuitive counter-fact \\
\hline 63 & 0 & 0 & 0 & 0 & 1 & 0 & 0 & 0 & - & Type C- Counter-intuitive counter-fact \\
\hline 64 & 0 & 0 & 0 & 0 & 0 & 0 & 0 & 0 & - & Type C- Counter-intuitive counter-fact \\
\hline
\end{tabular}


Figure 1

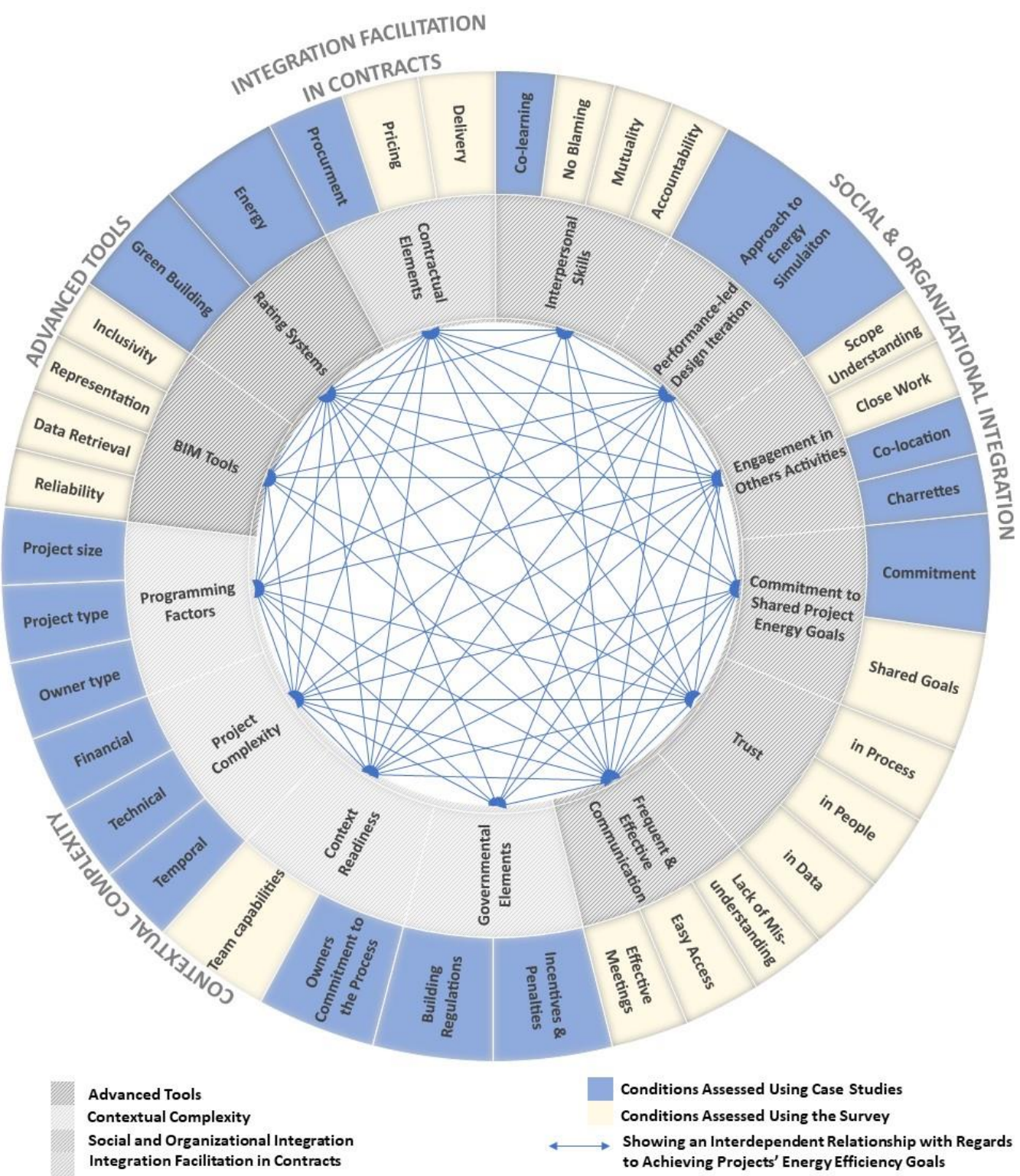

40 | P a g e 